\title{
Experimental study of the mechanical strength and the failure of multi-sheet, multi-material spot-welded assemblies under pure and combined loading conditions
}

\author{
Rim Chtourou ${ }^{1,2, *}$, Fahmi Chaari ${ }^{1}$, Gregory Haugou ${ }^{1}$, Nicolas Leconte ${ }^{1}$, Eric Markiewicz ${ }^{1}$, and Bassem Zouari ${ }^{2}$ \\ ${ }^{1}$ LAMIH, UMR CNRS 8201, University of Valenciennes, F-59313 Valenciennes Cedex 9 France \\ ${ }^{2}$ LA2MP, National Engineering School of Sfax (ENIS), B.P W3038, Sfax, University of Sfax, Tunisia
}

\begin{abstract}
Resistance Spot Welding (RSW) is widely used in the automotive industry thanks to its production convenience and cost effectiveness. Around four thousands spot welds are indeed employed to assemble the body-in-white. RSW of multiple sheets and combining multiple materials are increasingly realized. The UltraHigh-Strength Steels (UHSS) are particularly well suited for the entire range of structural parts requiring good crash resistance. However, the mechanical strength and the rupture of such new generation of RSW under multi-axial loadings is not yet well studied. The present work investigates the mechanical strength and the failure of a three-sheet spot welded assembly composed of two sheets of UHSS 22MnB5 and a third sheet of mild steel DX54D. An advanced experimental procedure is proposed for testing this assembly in pure and combined (tensile shear modes) modes I/II. Two types of specimen with different sheet thicknesses have been studied. The obtained results are analyzed to investigate the loading angle effect and the assembly configuration effect on the mechanical strength. Failure modes are also studied in relation with the increasing of the loading angle. Finally, the parameters of a macroscopic force-based failure criterion dedicated for FE crash modeling are identified.
\end{abstract}

\section{Introduction}

A new generation of multi-sheet multi-steel grade spotwelded assemblies has been recently introduced in the automotive industry, with the increase of the safety requirement. Also, lightweight automobile is the development trend in recent years, to reduce energy consumption and carbon emissions. In fact, the use of the Ultra HighStrength Steels (UHSS) in these spot welded assemblies makes it possible to reduce weight by $30 \%$ to $50 \%$ compared to conventional steel grades [1], while achieving the same crash performance. However, the mechanical behavior of this new generation of assemblies is not yet sufficiently studied. To the knowledge of the authors, most of published works for combined loadings concern two-sheet spot-welded assemblies [2-5]. When three-sheet assemblies are considered, only few works relate the study of the mechanical strength under quasi-static loading using conventional tensile-shear specimens [6-10]. In this context, this paper presents an experimental Arcan set up to investigate the mechanical behavior and the failure of the threesheet multi-steel grade spot-welded assemblies in pure and combined loading conditions. According to the assembled sheet thicknesses, two types of specimen have been studied to investigate the influence of the spot welded assembly configuration on the mechanical behaviour and on the failure mode. The first section presents the studied spot welded assemblies, and the experimental tests. The ob-

\footnotetext{
*e-mail: Rim.Chtourou@etu.univ-valenciennes-.fr
}

tained results and a discussion of the effect of the loading angle and the welded assembly configuration are presented in the second section. Finally, some conclusions are presented in the third section.

\section{Experimental tests}

\subsection{Studied three-sheet spot welded assemblies}

The studied spot welded assemblies consist of three-sheet assemblies of various thicknesses and involving two steel grades. According to the assembled sheet thicknesses, the specimens of the studied assemblies are classified in two lots:

- Lot A: (P1) is $2 \mathrm{~mm}$ thick and made of an ultra-high steel 22MnB5, (P2) is $0.65 \mathrm{~mm}$ thick and made of mild steel $\mathrm{DX} 54 \mathrm{D}$ and (P3) is $1.65 \mathrm{~mm}$ thick and made of 22MnB5 (Fig. 1).

- Lot B: (P1) is $2.5 \mathrm{~mm}$ thick and made of an ultra-high steel 22MnB5, (P2) is $1 \mathrm{~mm}$ thick and made of mild steel DX54D and (P3) is $1 \mathrm{~mm}$ thick and made of 22MnB5 (Fig. 2).

The mechanical properties of the two materials are presented in Table 1.

\subsection{Hardness measurement}

Vickers hardness testing was performed with Future Tech Hardness Tester. The applied force level for hardness measurement was equal to $300 \mathrm{~g}$. The averaged and linearised 


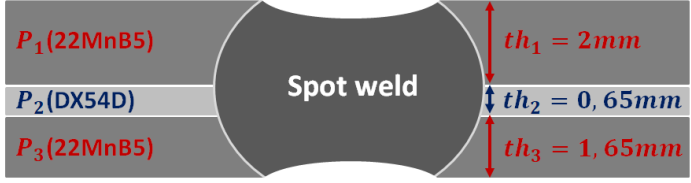

Fig. 1. Studied spot welded assembly-LotA

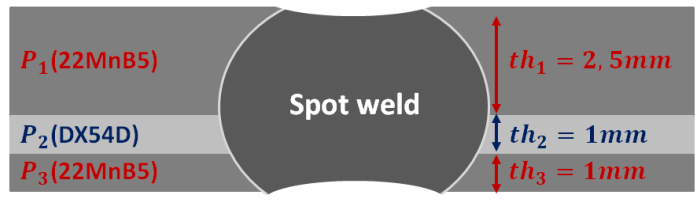

Fig. 2. Studied spot welded assembly-LotB

Table 1. Mechanical properties of sheets metals

\begin{tabular}{llll}
\hline & $\sigma_{y}(M P a)$ & $\sigma_{\max }(M P a)$ & $A(\%)$ \\
\hline$D X 54 D$ & 171 & 301.6 & 57 \\
$22 M n B 5$ & 1100 & 1500 & 6 \\
\hline
\end{tabular}

hardness distribution results revealed the nugget dimensions, and allows us to identify three zones of spot weld: Nugget, Heat Affected Zone (HAZ) and Base Material (BM) (Fig. 3).

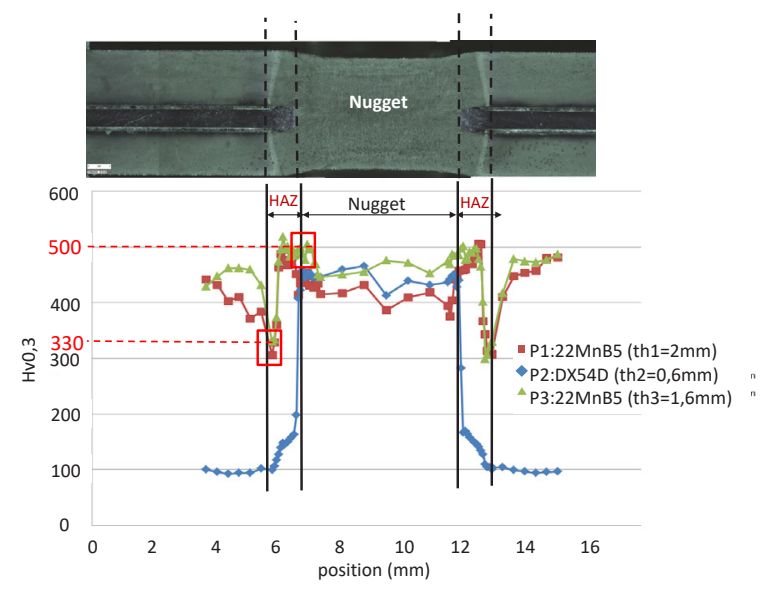

Fig. 3. Hardness distribution along the diametrical direction of manufactured spot weld joint

\subsection{Experimental device}

The tests are carried out on a high speed hydraulic machine (INSTRON VHS 65/20). The forces along the three main directions of the machine $\left(F_{x}, F_{y}\right.$ and $\left.F_{z}\right)$ are measured during the tests, using a triaxial load cell (Kistler 9367C) (Fig. 4). The displacement is obtained by a LVDT sensor.

A specific set up, based on Arcan principle, has been developed to link the specimen to the tensile machine. The loading modes are therefore combined and well controlled, with a reduced contribution of the plates strength surrounding the weld nugget in the macroscopic response. The angular position $\alpha$ between the loading directions (the vertical axis) and the normal to the surface of the specimen defines the tensile/shear ratio (Fig. 4). Note that an adequate test device is especially designed for each angular position $[12,13]$.

The experimental tests are performed such that the loading is applied on the two external plates of the specimen, at a loading velocity equal to $V=1 \mathrm{~mm} / \mathrm{s}$. The proposed device is made on a titanium alloy with a specific conception to minimize the inertia effects and to allow various dynamic loading.

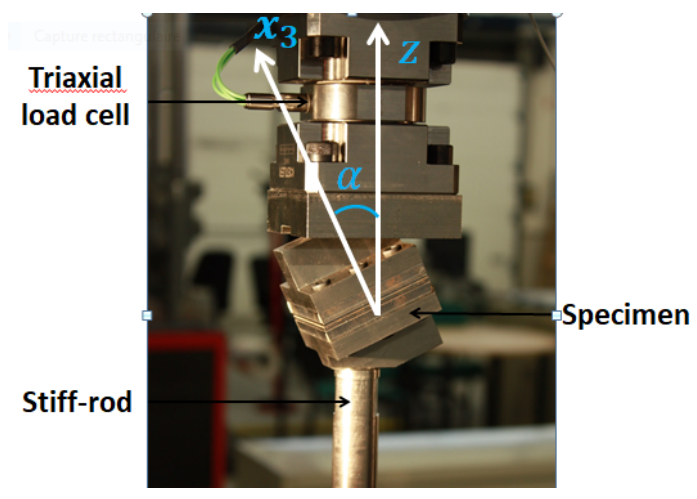

Fig. 4. Experimental device for three-sheet assembly tensile testing

\section{Experimental results and discussion}

Tanks to the proposed Arcan device, six loading angles are tested $\left(\alpha=\left[0^{\circ}, 30^{\circ}, 45^{\circ}, 60^{\circ}, 75^{\circ}, 90^{\circ}\right]\right)$. The exploitation of experimental results, allowed to identify the failure modes, to study the influence of the loading angle on the mechanical behavior, and to investigate the specimen configuration effect on the mechanical strength.

\subsection{Failure modes}

The post-mortem observations of the tested specimens allow to identify two main failure modes according to the loading angle: Pull-out failure mode and the Inter-facial failure mode.

- Pull-out failure mode: For this mode the failure occurs around the spot weld nugget. This failure mode is obtained for the pure and combined loading tests where the normal load is dominant during test. The normal load generates a stress concentration and leads to create a crack. Thus, the weld nugget is pulling out from the P3 layer (22MnB5, thickness $1.6 \mathrm{~mm})$. Figure 5 shows the section cut view of failed spot welds (post-mortem specimen) for the pure tensile mode $\left(\alpha=0^{\circ}\right)$.

- Inter-facial failure mode: For this mode the failure occurs inside the spot weld nugget. This failure mode is obtained for the pure shear test when the shear load is dominant during test. The shear load generates a stress concentration at the sheet/sheet interface into nugget level and leads to create a inter-facial crack that propagate through the spot weld nugget such as shown in figure 6 that presents a section cut view of failed spot 


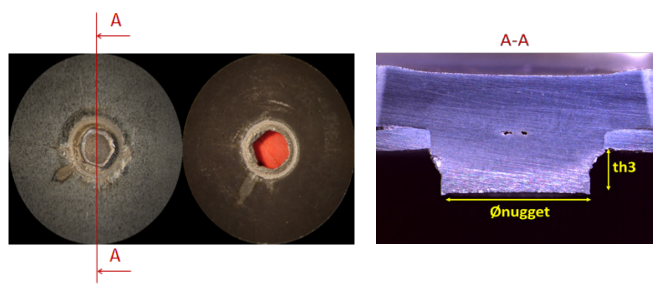

Fig. 5. Pull-out failure mode of three-sheet spot weld for tensile mode $\left(\alpha=0^{\circ}\right)$

welds (post-mortem specimen) for the pure shear mode $\left(\alpha=90^{\circ}\right)$.

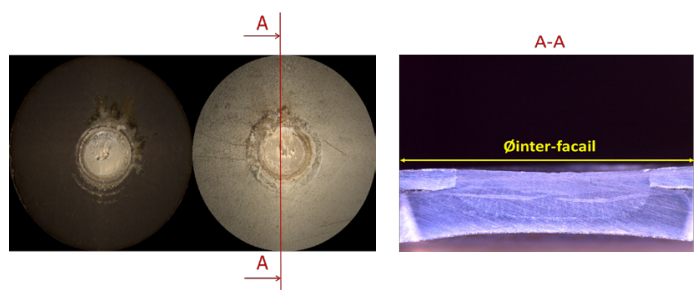

Fig. 6. Inter-facial failure mode of three-sheet spot weld for shear mode $\left(\alpha=90^{\circ}\right)$

\subsection{Effect of the loading angle on mechanical strength}

Figure 7 presents the exponential evolution of the peak load as a function of the loading angle. In fact, for $0^{\circ} \leq \alpha \leq 30^{\circ}$ the peak load increases slowly. Then, for $\alpha=45^{\circ}$, it increases rapidly up to reach its maximum value for pure shear $\left(\alpha=90^{\circ}\right)$.

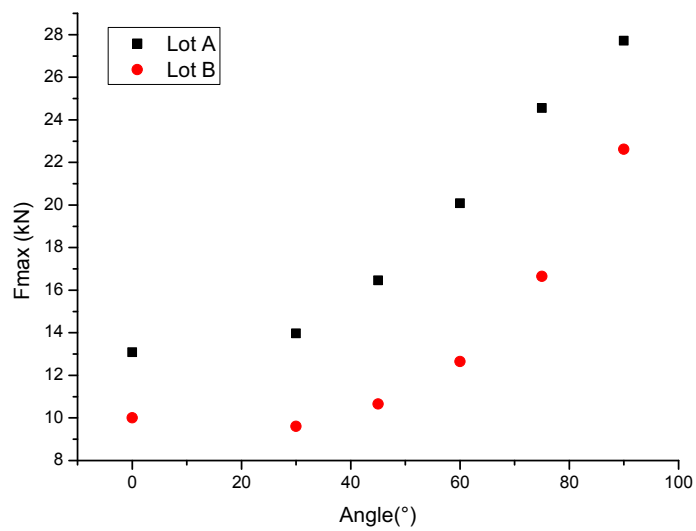

Fig. 7. Evolution of the maximum load as a function of the loanding angle

The increase of the peak load for the pure shear test is explained by the characteristics of the failure mode associated to each loading modes. In fact, for the Pull-out failure mode obtained for the pure and combined loading modes, the rupture occurs around the spot weld nugget in the HAZ, with a Pull-out failure section area estimated equal to $S_{\text {Pull-out }}=\pi \times \phi_{\text {nugget }} \times t_{3}$, where $\phi_{\text {nugget }}$ is the nugget spot weld diameter and $t h_{3}$ the P3 thickness (fig. 5). However, for the Inter-facial failure mode (for $\left.\alpha=90^{\circ}\right)$, the rupture occurs cross the nugget spot weld such as the Inter-facial failure section is estimated equal to $S_{\text {Inter-facial }}=\pi \times \phi_{\text {Inter-facial, }}^{2}$, where $\phi_{\text {Inter-facial }}$ is the spot weld diameter (fig. 6). For the Lot A, $S_{\text {Pull-out }} \simeq$ $14.45 \mathrm{~mm}^{2}<S_{\text {Inter-facial }} \simeq 50 \mathrm{~mm}^{2}$, which explains the increase of the peak load between the pure tensile test and the pure shear test.

\subsection{Effect of specimen configuration on the mechanical strength}

Two configurations of the spot welded assembly (Lot A and Lot B) are tested. The obtained results allowed to investigate the effect of the thicknesses of the assembled sheets on the behavior of the spot welded assembly. For the pure tensile test $\left(\alpha=0^{\circ}\right)$, the peak load obtained for a specimen of Lot $\mathrm{A}\left(F_{\max -\operatorname{LotA}}=13.08 \mathrm{kN}\right)$ is greater than that obtained for a specimen of Lot B $\left(F_{\max -\operatorname{Lot} B}=10 \mathrm{kN}\right)$ (Figure 7).

For $\left(\alpha=0^{\circ}\right)$, this peak load evolution can be explained by the change of failure mode between the specimens of the two Lots. In fact, for the Lot A the Pull-out failure occurs in the interface between the Heat-Affected Zone (HAZ) and the spot weld nugget as shows Figure 8. This failure zone corresponds to a hardness of about $500 \mathrm{Hv}$ (Fig. 3). However, for the Lot B, the Pull-out failure occurs in the interface between the Base Metal (BM) and the Heat-Affected Zone (HAZ) of the spot weld as shows Figure 9. This failure zone corresponds to a hardness of about $330 \mathrm{Hv}$ (Fig. 3).

The change of the failure zones hardness of the two Lots justifies the evolution of the mechanical strength. In addition to that, for Lot $\mathrm{A}$ the $\mathrm{P} 3$ thickness $\left(t h_{3-L o t A}=\right.$ $1.6 \mathrm{~mm})$ is thicker than that for Lot B $\left(t h_{3-L o t B}=1 \mathrm{~mm}\right)$, so obviously, the resistant section is larger, and consequently the peak load for a specimen of Lot A is greater than that obtained for a specimen of Lot B $\left(F_{\max -\operatorname{Lot} A}>F_{\max -\operatorname{Lot} B}\right)$.

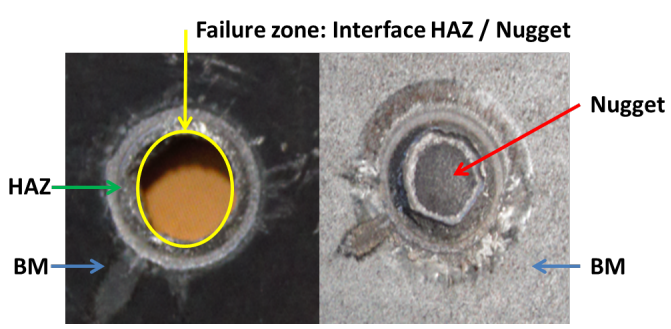

Fig. 8. Pull-out failure mode for Lot A

For the pure shear test $\left(\alpha=90^{\circ}\right)$, the peak load for a specimen of Lot A $\left(F_{\max -\operatorname{LotA}}=27.7 \mathrm{kN}\right)$ is also greater than that obtained for a specimen of Lot B $\left(F_{\max -L o t B}=\right.$ $22.5 \mathrm{kN}$ ) (Figure 7). The study of the failure modes for the two Lots can explain this evolution of the peak load. For the two Lots A and B, an Inter-facial failure mode is obtained in pure shear test. The failure occurs inside the 


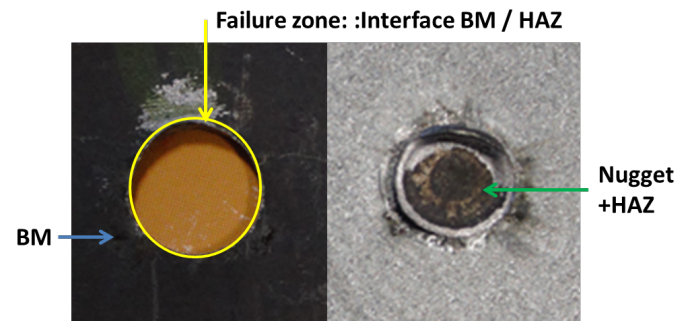

Fig. 9. Pull-out failure mode for Lot B

spot weld nugget at the sheet/sheet interface $F Z_{12}$. However, figure 10 shows that the sheet/sheet interface for Lot $\mathrm{A}$ is greater than that of Lot $\mathrm{B}\left(F Z_{12-L o t A m}=5.64 \mathrm{mmm}>\right.$ $\left.F Z_{12-L o t B}=.54 \mathrm{~m}\right)$. Considering the fact that the weld nugget resistance against the Inter-facial failure mode is determined by $F Z_{12}$, this explains the better resistance of the specimens of Lot A, for the pure shear test, compared to the specimens of Lot B.
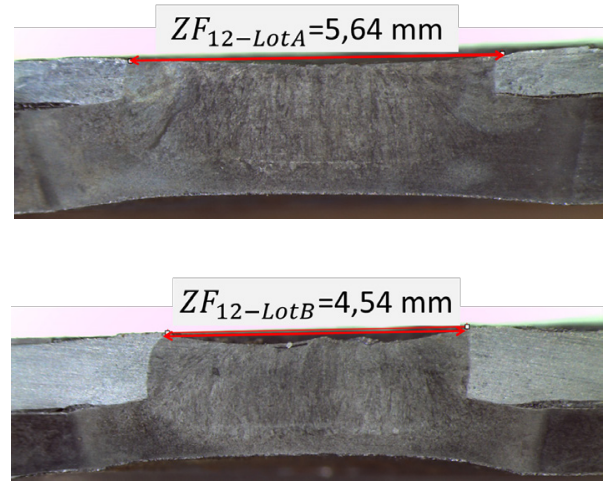

Fig. 10. Comparison of sheet/sheet interface dimension for Lot A and Lot B

The effect of the spot welded assembly configuration on the rupture envelope was also investigated. Figure 11 shows the evolution of the current normal force $N=F \cos (\alpha)$ according to the current tangential effort $T=F \sin (\alpha)$. We notice that the two envelopes are shifted. This shift comes back to the evolution of maximum effort depending on specimen type.

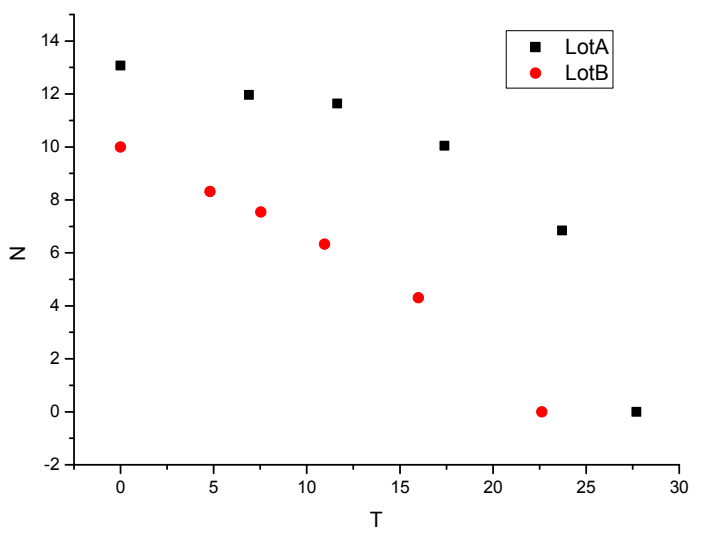

Fig. 11. Rupture envelope

\subsection{Macroscopic failure criterion}

As for two-sheet welded assemblies, a force based criterion Eq. 1 is proposed to identify the failure of the threesheet spot welded assemblies [11].

$$
\left(\frac{N}{N_{u}}\right)^{a}+\left(\frac{T}{T_{u}}\right)^{b}=1
$$

where $N_{u}=10 \mathrm{kN}$ is the ultimate normal force at failure obtained for $\alpha=0^{\circ}$, and $T_{u}=22.5 \mathrm{kN}$ is the ultimate tangentiel force at failure obtained for $\alpha=90^{\circ}, a$ and $b$ are exponents of the failure criterion identified from the experimental results of the combined loading tests.

The experimental results and the macroscopic failure criterion are presented by figure 12 .

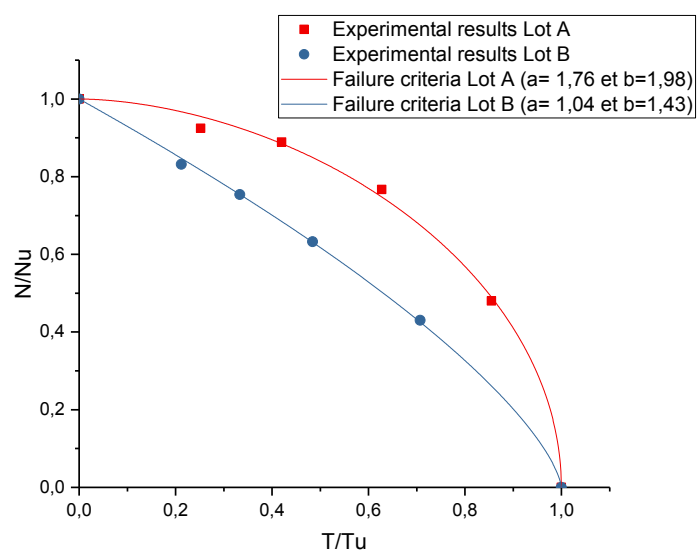

Fig. 12. Macroscopic failure criterioncriterion

\section{Conclusion}

An experimental procedure has been proposed in order to investigate the mechanical behavior of multi-materials multi-sheet spot welded assemblies in pure and combined tensile/shear modes.

Two principal failure modes are obtained depending to the loading angle. An exponential evolution of the peak load with the loading angle is observed for these assemblies.

According to the assembled sheet thicknesses, two configurations of spot welded assembly are studied. The obtained results show that the peak load increases with the thicknesses of third plate (P3) of the spot welded assembly.

Finally, a macroscopic failure criterion is proposed and compared to the experimental results.

\section{Acknowledgements}

This research is conducted through collaboration between the University of Valenciennes and the National Engineering School of Sfax. This collaboration is jointly financed in the frame of the Utique CMCU programme. The present research work has also been supported by the Nord-Pasde-Calais region, the European Community, the Regional 
Delegation for Research and Technology, the French National Research Agency, and by the Ministry of Higher Education and Research. The authors gratefully acknowledge the support of these institutions.

\section{References}

1. ArcelorMittal (2014). Steels for hot stamping-Usibor. The product catalogue, 2014.

2. Chao, YJ. (2003). Failure mode of spot welds: interfacial versus pullout. Science Technology Weld Joining, Vol. 8, pp. 133-7.

3. Lin, SH., Pan, J., Tyan, J., Prasad, P., A general failure criterion for spot-welds under combined loading conditions. International Journal of Solids and Structures, Vol. 40, 553964 (2003).

4. Dancette, S., Fabrègue, D., Massardier, V., Merlin, J., Dupuy, T., Bouzekri, M. (2010). Experimental and modeling investigation of the failure resistance of Advanced High Strength Steels spot welds. Engineering Fracture Mechanics, Vol. 78, pp. 2259-2272.

5. Langrand, B., Markiewicz, E. (2010). Strain-rate dependence in spot welds: Non-linear behaviour and failure in pure and combined modes I/II. International Journal of Impact Engineering, Vol. 37, pp. 792-805.

6. Nielsen, C.V., Friis, K.S., Zhang, W., Bay, N. (2011). Three-Sheet Spot Welding of Advanced High-Strength Steels:The weldability of thin, low-carbon steel to two thicker, high-strength steels is studied through factorial experimentation and statistical analysis. Welding Research, Vol. 90, pp. 32-40.

7. Tavassolizadeh, A., Marashi, S.P.H., Pouranvari, M. (2011). Mechanical performance of three thickness re- sistance spot welded low carbon steel. Materials Science and Technology, Vol. 27, pp. 219-224.

8. Pouranvari, M., Marashi, S.P.H. (2011). Failure Behavior of Three-Steel Sheet Resistance Spot Welds: Effect of Joint Design. Journal of Materials Engineering and Performance, Vol. 16.

9. Pouranvari, M., Marashi, S.P.H. (2012). Weld nugget formation and mechanical properties of three-sheet resistance spot welded low carbon steel. Canadian Institute of Mining, Metallurgy and Petroleum, Vol. 51, pp. 105-109.

10. Wei, S.T., Liu, R.D., Lv, D., Lin, L., Xu, R.J., Guo, J.Y., Wang, K.Q., Lu, X.F. (2015). Weldability and mechanical properties of similar and dissimilar resistance spot welds of three-layer advanced high strength steels. Science and Technology of Welding and Joining, Vol. 20, pp. 20-26.

11. Lee, Y., Wehner, T., Lu, M., Morrissett, T., Pakalnins, E., Ultimate trength of resistance spot welds subjected to combined tension. Journal of Testing and Evaluation, Vol. 26, 213-219, (1998).

12. Chtourou, R., Leconte, N., Chaari, F., Haugou, G., Markiewicz, E., Zouari, B. (2017). Macromodeling of the strength and failure of multi-layer multi-steel grade spot welds : connector formulation, assembly model and identification procedure. Thin-Walled Structures, Vol. 113, pp. 228239.119

13. Chtourou, Haugou, G., R., Leconte, N., Zouari, B., Chaari, F., Markiewicz, E. (2015). Experimental characterization and macro-modeling of mechanical strength of multi-sheet and multi-material spot welds under pure and mixed modes I and II. EPJ Web of Conferences, Vol. 94, pp. 01032. 
